\title{
A Common Currency Peg in East Asia? Perspectives from Western Europe
}

\author{
Hwee Kwan CHOW \\ and \\ Yoonbai KIM $^{*}$ \\ National University of Singapore \\ University of Kentucky \\ and \\ National University of Singapore
}

April 2002

\begin{abstract}
In this paper we investigate the feasibility of a common currency peg in East Asia from the perspective of Western European countries. We find that domestic outputs of East Asian countries are strongly influenced by country-specific shocks while regional shocks are far more important in European countries that have joined the Economic and Monetary Union. The results are robust to various changes in specifications of the model. They suggest that East Asian countries are structurally different from each other and thus more likely to be subject to asymmetric shocks. Based on optimum currency area grounds, a common currency peg in East Asia would be more costly and difficult to sustain.
\end{abstract}

JEL classification: F33, F41

\footnotetext{
* Corresponding author: Department of Economics, University of Kentucky, Lexington, KY 40502 (PH) 859-2572838. (FAX) 859-323-1920. (Email) ykim01@uky.edu.

We thank Reiny Iriana for her research assistance, Yung-hsiang Ying for his help with the data, two anonymous referees for their valuable comments, and Emily Cremers for editorial improvement. The remaining errors are our own. This research was supported by University Research Grant (No. 3992097) at the National University of Singapore.
} 


\section{Introduction}

The fixed exchange rate system has been assigned at least partial blame for financial crises that appear to be happening with increasing frequency. At the same time, some forms of fixed exchange rate arrangements have been adopted or actively considered for adoption in other contexts, the Economic and Monetary Union (EMU) in Europe being a most recent and dramatic example. These observations serve to highlight the pros and cons of fixed exchange rate systems. An irony is that, in East Asia (EA) where the financial crises of 1997 ended the de facto pegging to the US dollar for several countries, pegging to a common currency or basket of currencies is being promoted as a means to financial stability and as a preventive measure against future crises in the region. Tying the national currency to an international anchor currency may enhance the credibility of anti-inflation policy but will require the loss of flexibility in monetary and exchange rate policy. Given the costs and benefits of fixed exchange rates, would tight pegging to the US dollar, the yen, or some composite currency be desirable for EA? In this paper, we investigate the feasibility and desirability of such an arrangement.

The theory of optimum currency areas (OCA) lists conditions regarded as crucial for the success of a common currency in a region. These conditions include the symmetry of shocks across countries (Mundell, 1961), openness of the economies (McKinnon, 1963), and well-diversified economies (Kenen, 1969), all of which tend to reduce the occurrence of relative price changes among members of a currency area. In addition, labor mobility and wage flexibility would contribute to its smooth functioning. Later authors emphasize the need for a supra-national government body able to conduct interregional transfers. (See De Grauwe, 1997, for a survey.)

EA economies seem fairly well integrated both in trade and finance. Eichengreen and Bayoumi (1999) find that, on standard OCA grounds, they seem to be more or less as plausible candidates for internationally harmonized monetary policies as the members of the European Union. Arguments in favor of a common currency peg for East Asia include the following facts: (1) several but not all of countries 
are small and very open; (2) in addition to a substantial number of intense bilateral trade links, intraregional trade is high and rising (Goto and Hamada, 1994); (3) cross-border investment flows of foreign direct investment are extensive and a large portion of the associated debt denominated in yen (Kohsaka, 1996); (4) the adjustment to shocks is relatively speedy and appears to be faster even than Europe. This is aided by flexible labor markets with high labor mobility. Together, these structural characteristics of the EA countries suggest that the benefits from a common currency arrangement might be large while the costs from sacrificing independent monetary policy relatively small.

Empirical studies of financial data - exchange rates, interest rates, and stock prices- suggest a high and increasing degree of financial integration between EA countries and Japan although it is unclear whether Japan, rather than the U.S., represents the regional anchor. Aggarwal and Mougoue (1993) and Tse and Ng (1997) report cointegration among the exchange rates of Asian currencies. Chinn and Frankel (1995) find that real interest rates of EA are cointegrated with either the US rate, the Japanese rate or both. Phylaktis (1999) finds evidence of stronger cointegration among post 1980 real interest rates of the US, Japan and each of five Pacific Basin countries than in earlier periods.

In terms of observed exchange rate policy, however, evidence for the position of the yen vis-à-vis the dollar in EA is weak. Empirical studies reveal that the relative role of the yen is somewhat limited even in the 1990s. Seminal studies by Frankel (1993) and Frankel and Wei (1994) find that in the determination of EA exchange rates, the US dollar continues to be dominant and evidence of an increasing role for the yen is relatively faint. Fukuda (1996) shows that the invoice ratios of the yen are much lower than those for the dollar. Benassy-Quere (1999) reports that volatility against the dollar is uniformly lower than volatility against the yen.

Previous studies on the feasibility of a common currency peg in EA are quite divided. ${ }^{1}$ In Frankel and Wei (1994) and McKinnon (2000), EA is shown to be more like a dollar bloc despite evidence of an increasing role for the yen. Dornbusch and Park (1999) reject the necessity of a nominal anchor of any form as countries in the region have no major problems with inflation. Instead, they recommend a high 
degree of flexibility in exchange rate management to accommodate rapid economic growth and large real exchange rate changes. Eichengreen and Bayoumi (1999) find that EA countries satisfy the OCA criteria just as well as the EMU countries. They argue, however, that EA lacks important elements of successful monetary integration such as sound financial systems, political network, and a long history of integrationist tradition. Kwan (1994) strongly advocates a yen bloc in EA, Korea and Taiwan in particular, on the grounds that pegging to the yen may benefit countries that have export structure similar to that of Japan by stabilizing output. Williamson (1999) argue that EA countries are sufficiently competitive with each other in international trade and thus recommend some sort of joint exchange rate arrangement, such as a common basket peg, to avoid competitive exchange rate adjustments and to stabilize effective exchange rates. Noting the wide variety of existing exchange rate systems within the region, he recommends the collective arrangement to be accompanied by wide bands and flexible changes within the peg.

In this paper, we investigate the feasibility of a common currency peg in East Asia. Given that 12 European countries have recently proceeded to form a single currency area, the EMU is a natural standard of comparison. We apply the theory of OCA and consider a model in which relevant shocks are classified as being global, regional or country-specific. The importance of regional shocks - that is, symmetric shocks within the region - would constitute a prima facie case in favor of a currency peg. If, on the other hand, country-specific shocks are prevalent and uncorrelated across countries, a currency area would be difficult to sustain. If global shocks are predominant, a more global arrangement might be more attractive. For European countries, we consider Germany to represent the region. For EA, we consider various possibilities although we begin with the assumption that Japan plays the role of Germany. For both groups of countries, the U.S. is considered to represent the global economy.

To anticipate the empirical results of this paper, we find that domestic outputs of East Asian countries are strongly influenced by country-specific shocks whereas regional shocks are far more important in European countries that have joined the EMU. The results are robust to various changes in 
model specifications. These findings suggest that EA countries are structurally different from one another and thus more likely to experience asymmetric shocks than the EMU member countries. Based on optimum currency area grounds, it can be expected that a common currency peg in East Asia would be more costly and difficult to sustain.

The balance of the paper is organized as follows: Section 2 describes the model and discusses the estimation method. Section 3 reports the estimation results with detailed comparison with previous studies summarized in Section 4. Robustness of the results is examined in Section 5. Section 6 concludes with some discussion.

\section{A Model}

Domestic output, $y^{d}$, is subject to 3 types of shocks: global, regional, and country-specific. $\left(u^{g}, u^{r}\right.$, and $\left.u^{d}\right)$ :

$$
\Delta y_{t}^{d}=\beta_{0}+\beta_{1}(L) u_{t}^{g}+\beta_{2}(L) u_{t}^{r}+\beta_{3}(L) u_{t}^{d}
$$

where $\beta_{i}(L)=\beta_{i 0}+\beta_{i 1} L+\beta_{i 2} L^{2}+\cdots$, is a polynomial function of the lag operator, $L{ }^{2}$ Global shocks affect economies both inside and outside the regional boundary. The two large oil price increases of the 1970s may be termed global shocks. Regional shocks are common to the economies within the region. German unification of 1989 and the resulting fiscal expansion constitute a regional shock for European countries. In East Asia, large fluctuations in the yen-dollar exchange rate seem to have been a common, important source of disturbance. (Kwan 1994) Country-specific shocks are unique to a particular economy. They may be either from aggregate demand shocks that are associated with monetary or fiscal policies or supply shocks on productivity or the terms of trade.

Regional shocks are expected to be important in a small open economy or in an economy with an economic structure similar to its trading partners or neighbors. For a country considering membership in a currency union, the prevalence of regional shocks - which affect countries in the region in a symmetric fashion - should provide a positive impetus. On the other hand, the costs associated with a loss of 
monetary independence and flexible exchange rate adjustments could be heavy if dominant shocks are country-specific shocks and therefore uncorrelated across the region. External shocks can extend regional boundary. As long as such shocks affect all countries in the same direction, a global rather than regional arrangement might be a better course of action in dealing with such shocks. In the context of East Asia, for instance, if global shocks (say, affecting US output) are relatively more important than regional ones (say, affecting Japanese output), forming a dollar bloc may be a better policy choice than forming a yen bloc.

In related studies, Bayoumi and Eichengreen (BE, 1993) apply the aggregate demand-aggregate supply model. They maintain that demand disturbances reflect macroeconomic policy choices of the country including exchange rate policy and thus are not expected to be invariant with respect to the exchange rate regime. On the other hand, supply shocks are considered to be more structural and thus less sensitive to the choice of an exchange rate arrangement. If supply shocks are highly correlated or symmetric within a region, then the region would be a good candidate for a currency union. If not, that is, if supply shocks exhibit asymmetry via low levels of correlation, the region would be a poor candidate for a currency union.

One difficulty of the BE model is that when supply shocks are correlated across countries, the model cannot distinguish whether the shocks are regional, global, or simply correlated local shocks. The prevalence of regional shocks or correlated local shocks may justify common monetary policy within the region. On the other hand, if global shocks are dominant and if they similarly affect all economies inside and outside the region, a more global arrangement might be necessary. Another problem is the assumption that supply shocks tend to be invariant with respect to regime changes. Frankel and Rose (1998) argue that countries are likely to face more similar shocks as trade increases, implying that supply shocks will become more highly correlated as economic integration progresses. As pegging to a common currency reinforces and is reinforced by trade interdependence within the region, supply shocks are expected to become more correlated over time. Note that a similar critique applies to our model as well. 
For instance, increases in intra-regional trade are likely to increase the role of regional shocks relative to country-specific shocks. The moral is that no single classification scheme is optimal for all purposes and one needs to investigate various models.

The above discussion suggests that a model of regional integration needs to consider a minimum of the three types of shocks. For instance, one could entertain a larger model that more finely differentiates domestic disturbances into country-specific demand shocks and country-specific supply shocks. For simplicity, such classification is not considered below.

Consider a 3-variable model with global, regional and local outputs: $y^{g}, y^{r}$, and $y^{d}$. They are related to three structural shocks as follows:

$$
\left(\begin{array}{c}
\Delta y_{t}^{g} \\
\Delta y_{t}^{r} \\
\Delta y_{t}^{d}
\end{array}\right)=\left(\begin{array}{lll}
A_{11}(L) & A_{12}(L) & A_{13}(L) \\
A_{21}(L) & A_{22}(L) & A_{23}(L) \\
A_{31}(L) & A_{32}(L) & A_{33}(L)
\end{array}\right)\left(\begin{array}{c}
u_{t}^{g} \\
u_{t}^{r} \\
u_{t}^{d}
\end{array}\right)
$$

where $A_{i j}(L)=a_{i j}^{0}+a_{i j}^{1} L+a_{i j}^{2} L^{2}+\cdots$. In the matrix form,

$$
\Delta y_{t}=A(L) u_{t}
$$

We assume that the structural shocks are uncorrelated and of unit variance: $\operatorname{Var}\left(u_{t}\right)=I$. Structural shocks are unobserved. The following identifying restrictions are employed to recover them from reduced-form innovations: (1) neither regional nor country-specific shocks have long-run effects on global output; (2) country-specific shocks have no long-run effects on regional output. These restrictions are generalizations of the small-economy assumptions that are often made in international economics. Thus, an economy is considered to be small in a region and the region is only a small part of the global economy. In terms of the coefficients of the $A(L)$ matrix, these restrictions amount to $A_{12}(1)=A_{13}(1)=A_{23}(1)=0$ where $A_{i j}(1)=a_{i j}^{0}+a_{i j}^{1}+a_{i j}^{2}+\cdots$. The estimation of a model with these types of restrictions is well known and thus omitted. 
The three structural shocks may mix various underlying shocks. For instance, due to the identifying restrictions, transitory global shocks that have no long-run effect on global output could be classified as regional or local shocks. Similarly, transitory regional shocks may be classified as local. It is also likely that region-wide shocks can be no more than country-specific shocks that are transmitted across the region through trade in goods or due to policy coordination, contagion, or any other reason. With our identifying restrictions, all these shocks are likely to be classified as "regional" in the sense that outputs of the region are similarly affected. Whether we call them regional shocks or correlated country-specific shocks does not matter for our purpose. What we observe is that outputs in the region move together and we try to investigate how important these shocks are relative to other types.

The above empirical model is an application of the structural VAR method that has been developed by, inter alia, Blanchard and Quah (1989), and King, et al (1991). It relies on the long-run effects of structural shocks derived from the neutrality of demand shocks. Although such long-run restrictions tend to be less controversial and more readily accepted than other assumptions, they are not without criticisms. Faust and Leeper (1997) point out that structural inferences under the long-run scheme may not be reliable as the long-run effects of shocks are imprecisely estimated in finite samples and the longrun identification scheme transfers this imprecision to the estimates of other parameters of the model. Another criticism is that the estimated disturbances will commingle the underlying disturbances. For instance, country-specific shocks can be of demand or supply type, monetary or non-monetary. Whether these various shocks will be encompassed as country-specific shocks is a moot question. One could employ a larger model to avoid the problem. An alternative, as recommended by Faust and Leeper (1997), is to check for consistency of results across various small models. (See Rogers, 1998, for related discussion.)

To address these criticisms, we try various specifications and identifying assumptions and compare results across different models and report in Section 5. 


\section{Empirical Results}

In this study, output is represented by industrial production. Fifteen European countries - Austria, Belgium, Denmark, France, Ireland, Italy, Netherlands, Finland, Greece, Norway, Portugal, Spain, Sweden, Switzerland, and the U.K. - and seven East Asian countries - Hong Kong, Indonesia, (South) Korea, Malaysia, Philippines, Singapore, and Taiwan - are investigated. (Of the so-called EA9, China and Thailand are omitted due to insufficient data.) For European countries, German output is used as a proxy for regional output. For East Asian countries, Japanese output is used as a proxy for regional output. (In Section 5, we also consider other choices for regional output.) For both groups, the US represents the global economy. Quarterly data are obtained from IFS CD ROM for most countries. ${ }^{3}$ The time series starts at 1965:1 for Europe with the exception of Austria and Denmark, both of which start at 1968:1. For EA, it starts at 1971:1 with the exception of the Philippines (1981:1), Hong Kong (1982:1) and Indonesia (1979:1). In all cases for both Europe and EA, the series ends at 1997:1. Seasonal adjustment was carried out using the Census X-11 method for Hong Kong, Indonesia, Malaysia, Singapore and Austria. Finally, the benchmark model assumes that all outputs are nonstationary and the set of global, regional and domestic outputs are noncointegrated for each country. ${ }^{4}$

For Europe, we consider 2 groups. The first group consists of six original members of the exchange rate mechanism (ERM: Belgium, Denmark, France, Ireland, Italy, and the Netherlands). Austria is also included in this group, as the schilling has maintained a nearly fixed exchange rate with the mark over a long period. All these countries have joined the EMU in 1999 except Denmark. The second group consists of countries that joined the ERM at later dates (Finland, Portugal, Spain, and Greece), countries that are members of the EU but are not part of the currency union (Sweden, and the U.K.) and countries that are not members of the EU (Norway and Switzerland).

\section{$\underline{\underline{\text { Table } 1 \text { Here }}}$}

Table 1 reports the variance decomposition of forecast errors at the 4- and 20-quarter forecast horizons for Europe and East Asia. Global, regional and local shocks are denoted by "U-G", "U-R" and 
"U-D," respectively. 4 (20) quarter responses are taken as short-term (medium-term) effects. In all cases, the VAR model is estimated with four lags. Given the large number of countries and cases to be estimated, a uniform lag length is used for convenience. Using less than four lags often leaves serial correlation among the residuals. In Table 1, variance decompositions are reported only for domestic output since global output and regional output are mainly explained by global and regional shocks, respectively. Interesting differences emerge for variance decomposition of domestic output. In the first European group, regional shocks explain 30 percent or more of output variations in the short run and more than 40 percent in the medium run. The importance of regional shocks is highest in Austria, Belgium, and the Netherlands where more than 50 percent of medium-term output variations are due to regional shocks and the effects of global shocks are minimal, explaining 10 percent or less. Interestingly, regional shocks become dominant in the medium run even in France, which is often considered too large to belong in a currency area with Germany. They are somewhat less important in Denmark. Ireland and Italy are exceptions in this group. In both countries, domestic shocks dominate and explain more than 50 percent of short-run fluctuations in output.

In sharp contrast, country-specific shocks are dominant over regional and global shocks in the second group. Regional shocks are much less important than for the first group. With the exception of Switzerland, regional shocks explain no more than 35 percent in the 20 -quarter horizon. It is also interesting to note that, among this group of countries, regional shocks are relatively more important in Spain, Portugal and Greece - that joined the EMU - than in other countries. Among the group, countryspecific shocks are far more dominant in Finland, Norway, and Sweden reflecting perhaps their resourcedependent economies.

There are striking differences between Europe and East Asia. For the latter, dominant shocks for domestic output are country-specific in all countries and in all horizons, explaining more than 60 percent in most cases. Regional shocks are far less important than in the EMU group, explaining less than 10 percent of output variation in most cases. Taiwan records the highest share of regional shocks at 27 
percent in the short run. They are also consistently dominated by global shocks especially in longer horizons.

Given the size and openness of some countries and anecdotal evidence of economic dependence on Japan, the minimal role of regional shocks is surprising. The finding that global shocks are far less important in EA than in many European countries is also surprising given the more dominant role of the U.S. and the dollar in the region than in Europe. It might be that the dynamics of industrial production for each EA country differs significantly and furthermore is neither synchronized with that of Japan nor the U.S. No doubt the empirical result is related to the fact that Japanese industrial production has hardly grown since the early 1990s while other EA economies have continued their rapid growth at least until the 1997 financial crisis. Moreover, the EA countries also have growth experiences that are sufficiently different from each other in terms of timing, resource dependence and industrial structure although they may share the common "growth miracle".

Another interesting difference is that in EA countries, global and regional shocks tend to become less important over the medium run than in the short run. See, for instance, the role of regional shocks in Taiwan and that of global shocks in Korea. This suggests that a large portion of the external shocks experienced by these countries is temporary. This may reflect the fact that most countries have been able to maintain rapid growth while they nevertheless suffer business cycles related to external conditions, which are essentially temporary.

\section{$\underline{\underline{\text { Table } 2 \text { Here }}}$}

To investigate the stability of variance decompositions, we split the sample into two sub-periods. The data are divided at 1979:1 for European countries, which marks the formation of the European Monetary System. For EA countries, the first period lasts until 1984:1, which roughly corresponds to the midpoint of the data. For brevity, we report only variance decompositions for domestic output and, for European countries, only summary statistics. Interesting differences emerge in Table 2. Among European countries, we observe drastic differences between core and non-core groups and between EMU and non- 
EMU countries. In the core group of Europe, which consists of Austria, Belgium, the Netherlands, and France, nearly 60 percent of variations in the medium run are explained by regional shocks while the effects of global shocks are minimal, explaining less than 10 percent. In the non-core group, which includes both "periphery" and non-EU countries, regional shocks are much less important than in the core group. Instead, country-specific shocks are dominant over regional and global shocks.

Of 15 European countries, nine have joined EMU since it launched in 1999. Three countries (Denmark, Sweden, and the UK) decided to opt out, Greece was initially disqualified but joined by 2000, and two (Switzerland and Norway) are not EU members. The importance of regional shocks has been very different for the two groups. In EMU countries, there is a slight increase from 42 to 46 percent while in non-EMU countries it declined sharply from 40 to 24 percent. This contrast suggests that the improvement in the qualifications to join in a common currency area is most likely related to the similar economic policies imposed under the Maastricht Treaty, such as caps on inflation and interest rates as well as government debt and deficits.

In East Asia, sub-period comparison is feasible for only four countries due to a lack of sufficient data. For countries with short data sets, whole period estimates are reported under period II. It is clear that global shocks became far less dominant in period II than in period I. This is expected because period I is characterized by the fixed exchange rate arrangements under the Bretton Woods system - which probably helped the transmission of monetary shocks - and common shocks such as the two rounds of oil shocks. (A similar change is observed in most but not all European countries.) Regional shocks remain secondary to domestic shocks in period II, responsible for less than 10 percent of output variations in Hong Kong, Malaysia and Taiwan and less than 30 percent in all cases. With the exception of Taiwan, the region seems to be slightly more integrated in the later period - the change is minimal, however, and only Singapore and Korea exhibit a notable increase. It is noteworthy that the importance of regional shocks in EA in both periods is in general much lower than that in European countries in period I (that is, before the formation of the EMS). It is also interesting to note that country-specific shocks became more 
important in EA in period II largely at the expense of global shocks. This result is surprising given the scope of liberalization of trade and financial markets, which is expected to have made the countries more open and vulnerable to increased capital flows and other external shocks.

\section{Comparison with Other Studies}

BE (1997) operationalize the theory of OCA and construct an index based on the degree of exchange rate variability predicted by 4 factors - the asymmetry of output disturbances, the dissimilarity of the composition of exports, the extent of bilateral trade, and the size of the economy. Smaller values of the index would suggest that countries better approximate an OCA. It would be interesting to compare the rank of countries based on our scheme with that based on the BE's OCA index. To distinguish this from another index that is discussed below, we designate it as BE1 index. In our scheme, given the low possibilities of correlated country-specific shocks, the importance of regional shocks in domestic output would be the main indicator of regional integration and thus the suitability of joining a currency area in the region. When we use BE1 index of 1987 together with our whole period results using the 20-quarter variance decomposition, we obtain the Spearman rank correlation coefficient 0.64 which is significant at the $1 \%$ level. ${ }^{5}$ Countries in Group I rank high in both indices while most countries in Group II rank low. Main differences between the two rankings involve France and Ireland. France, a relatively large country, is ranked low according to the BE1 index as it is heavily influenced by country size and the importance of bilateral trade. On the other hand, it is strongly influenced by the importance of regional shocks in our results and thus ranked high. Ireland is much the opposite case. Due to size, Irelands ranks high in the BE1 index. Our results indicate that the country is fairly independent from Germany and the EMU region. Anecdotal evidence also suggests contrary business cycle movements relative to the EMU region (e.g., in the early 1990s, Ireland experienced a high-growth boom while her Continental neighbors were suffering from recessions). 
Eichengreen and Bayoumi (EB, 1999) report a similar index for EA. ${ }^{7}$ As with the case of Europe, the index is strongly influenced by country size, thus ranking Singapore and Hong Kong highest and Indonesia the lowest. Most surprisingly, their indices for EA are close to those of Denmark and France although they are greater than those for small European countries. Based on this evidence and others, they concludes that "on standard OCA grounds, the economies of East Asia would seem to be more or less as plausible candidates for internationally harmonized monetary policies as the members of the European Union.” (p. 360) ${ }^{8}$ Our assessment of OCA in EA is lower than that of EB. (Not surprisingly, the Spearman rank correlation coefficient between two rankings of EA is also statistically insignificant.) The role of regional shocks on domestic output in EA is in general much lower than that of Europe's Group I and more similar to that of the European countries that had some difficulties joining the EMU or that decided not to join in the first round.

Since both the methodology and the data are different, it is difficult to explain the sources of different assessments of OCA qualifications of EA countries between EB (1999) and ours. They used annual data while we use quarterly data. As income and price data, they adopted real GDP and the GDP deflator whereas we use industrial production. (For the purpose of comparison, we also employed CPI data.) Moreover, their model is more comprehensive and utilizes more variables. Two differences in data might be responsible for the result. One difference is that the BE1 index emphasizes the "country size" and "openness" variables far more than ours. These are the main variables that do differ across countries more than other variables in their regression model. The other difference is that EB (1999) use annual data on real GDP and international trade, which are smoother and less volatile than quarterly industrial production data used in our study. Consequently, their index seems to be less sensitive to the asymmetry of structural shocks than ours.

In earlier studies, BE $(1993,1994)$ have devised another indicator of OCA compatibility focusing more exclusively on the symmetry of structural shocks, which designate as BE2 to distinguish it from the above one. They consider aggregate supply shocks to be more appropriate measure of structural shocks in 
that they reflect underlying private sector behavior and are more likely to be invariant with respect to alternative international monetary arrangements. A high (low) correlation of supply shocks of the home and the anchor countries suggests that the economies are subject to symmetric (asymmetric) shocks and thus are good (poor) candidates for a currency union. ${ }^{9}$

When fifteen European countries are ordered according to BE2, the rank correlation with our index is 0.79 . This suggests that correlated aggregate supply shocks in the BE model are well captured in our model as common regional shocks. EB(1999) also report that, in East Asia, the correlation of supply shocks between Japan and Korea and Taiwan is high, comparable to that of Europe's Group I countries with Germany, while it is much lower between in other countries. Thus, according to BE2, a currency area anchored by Japan is likely to include those two Northeast Asian economies.

\section{$\underline{\underline{\text { Table 3Here }}}$}

The comparison indicates that our model is quite comparable to BE2 index in that it provides a lower assessment of OCA in East Asia. They identify only Korea and Taiwan as suitable to form a currency union with Japan. (On the other hand, they find equally strong correlations among Southeast Asian countries such as Hong Kong, Indonesia, Malaysia, Singapore and Thailand and thus another potential group for a currency union.) In Table 1, Taiwan is shown to have the highest portion of domestic output explained by regional shocks among EA countries. Table 2 shows that Korea is most closely integrated with Japan in both sub-periods (although not in the whole period). The role of regional shocks in these two countries is lower than those of most Group II countries in Europe.

Although our model is fairly comparable to $\mathrm{BE}(1993,1994)$, there is no one-to-one correspondence. In an attempt to reconcile the difference, we reproduce the BE-type analysis with our data in Table 3. Note that BE used annual data for real GDP and the GDP deflator for the 1960-90 period in Europe and 1969-89 for East Asia whereas we employ quarterly data on industrial production and CPI data and also cover the more recent period up to 1997. Reflecting perhaps that the underlying shocks are less correlated in our higher-frequency (quarterly) output and price data, correlations of both supply and demand shocks 
are generally lower in Table 3 than for corresponding figures in BE $(1993,1994)$. Nonetheless, one can see clearly that correlations of both AS and AD shocks are higher for the Group I countries of Europe than for either the Group II or EA countries. (The low correlation coefficient reported for the Netherlands is difficult to explain, however.) Among EA countries, Taiwan seems to be the only country whose correlation in AS shocks with Japan approaches the level of Group I countries. Using the U.S. or G3 (the average of the U.S., Japan, and Germany) as the regional anchor produces little difference. Correlations of demand shocks appear somewhat higher. Taiwan, and perhaps, Malaysia and Singapore, appear to share more similar demand shocks with Japan.

Table 3 suggests that the industrial production data employed in this study are more likely to accentuate the differences in the industrial and trade structure of the countries than the GDP data used in $\mathrm{EB}$, especially in fast growing countries with tremendous structural transformation. Moreover, the inclusion of the more recent data in our study seems to reduce the role of regional shocks represented by Japanese output. During the 1990s, the Japanese industrial production had hardly grown at all while other Asian economies maintained fast growth until the 1997 crisis. Consequently, East Asian countries appear more subject to idiosyncratic shocks in comparison with European counterparts.

\section{Robustness}

Whether a shock can be classified "regional" or of any other type depends on the identifying scheme. In our case, the identifying restrictions are based on the long-run effects of structural shocks. Needless to say, this is not the only or even the least arbitrary identification scheme available. We thus try several alternative schemes. The first alternative model, M1, is a standard VAR model in first differences where structural shocks are recovered using the Choleski decomposition method. It imposes both that regional shocks have no contemporaneous effects on global output and that domestic shocks have no contemporaneous effects on global or regional output. The second alternative, M2, imposes the exogeneity restrictions. In this model, global output is completely explained by own shocks with no 
feedback from either regional or domestic output. Regional output is affected by lagged values of global output and itself. ${ }^{10}$

In the third alternative, M3, we add the price level as a fourth variable. Country-specific shocks in M3 consist of aggregate supply shocks and aggregate demand shocks. As in Bayoumi and Eichengreen (1993), we impose the restriction that aggregate demand shocks have no long-run effects on output. The same hierarchical restrictions apply as in the benchmark model. Consequently, the long-run effects matrix is lower triangular.

For East Asia, we also try various definitions of regional and global output. In M4, global output is a geometric average of U.S. and German output with weights 4 and 3, respectively. Regional output is a geometric average of Japan, Korea, Taiwan, Malaysia and Singapore, which are selected mainly because they have longer data sets than other countries. Weights are based on real GDP of 1990 (purchasing power parity measure using international prices as reported in Penn World Table). In M5 and M6, we abolish the distinction between global and regional economies and the model degenerates into a twovariable specification. This exercise is motivated by the observation that a single anchor currency such as the German mark in Europe is not obvious in EA although the dollar and the yen are considered to play key roles. In M5, regional output is represented by a weighted average of the U.S., Japan and Germany with weights of 4, 3, and 3. (A similar weighting scheme has been proposed by Williamson, 1999.) In M6, U.S. output is used as regional output.

\section{$\underline{\text { Table } 4 \text { Here }}$}

Table 4 compares variance decompositions from the various models for East Asia. It suggests that results are consistent across model specifications and variable definitions. (The results for Europe are omitted due to space considerations, but they also indicate consistency across various models.) As in the benchmark model, country-specific shocks are dominant and regional shocks least important in all three alternative models. (M3 for Indonesia is the only exception.) In the two-variable models of M5 and M6, the combination of global and regional shocks, which we may call external shocks, explains a larger 
share of domestic output variations in all countries except Hong Kong and Indonesia than the sum of the two estimated separately in the 3-variable models. Another interesting finding is that, in the majority of cases and most strongly indicated in Korea and Taiwan, regional shocks capture a greater share under M6 than under M5. (Indonesia shows no difference with respect to these variations. Similarly, the case of Hong Kong seems quite surprising. The effects of regional shocks are uniformly low in all cases regardless of the definition of the regional center.) This suggests that despite what regionally diversified patterns of trade in these countries may indicate, the EA economies, especially Korea and Taiwan, are heavily dominated by U.S. influence. An implication is that if the optimum currency area theory were the only guide for the choice of peg, a US dollar peg as suggested by McKinnon (2000) and Frankel and Wei (1994) might be preferable to a yen peg proposed by Kwan (1994) or a common basket peg favored by Williamson (2000).

\section{Conclusion}

In this paper, we applied the OCA theoretic criterion to investigate whether pegging to a common currency is a desirable option in East Asia. As regional anchor, we considered the yen, the dollar, and other possibilities. The EMU launched in 1999 naturally becomes a standard of comparison. In our model, the economy is subject to three types of shocks: global, regional and country-specific. Following the OCA literature, maintaining a pegged exchange rate (against the yen, the dollar or some composite currency) would be reasonable if an economy is heavily subject to common regional shocks. The pegging would be more costly if dominant shocks are country-specific.

Summarizing the main results of the investigation: we find that regional shocks are dominant in the EMU countries while other countries in Europe are more strongly influenced by country-specific shocks. (There are exceptions such as Ireland and Switzerland.) Also, perhaps reflecting further regional integration within Europe, regional shocks remain important or became more important in the more 
recent period than before among the countries that have joined the EMU. In East Asia, in sharp contrast to the EMU group, dominant shocks are country-specific and regional shocks are far less important.

For European countries, the results are strongly consistent with those of Bayoumi and Eichengreen (1997). They are also intuitive. Countries that have smoothly moved to the EMU in general have a large proportion of domestic output explained by regional shocks. For countries that either had difficulties joining the EMU, had periodic exchange rate realignments, or that decided not to join in the first round, country-specific shocks are dominant.

The results for East Asian countries contradict the previous study by Eichengreen and Bayoumi (1999) who find them almost as equally qualified as the EMU countries in terms of the OCA criteria. According to our results, regional shocks are much less important than in the EMU countries. The lack of importance of regional shocks in EA countries is similar to that of European countries - Ireland, Finland, Norway, Sweden, and the U.K. - which are characterized by idiosyncratic business cycles. Most of these countries have either not joined the EMU or joined with difficulties. The insignificance of regional shocks in the determination of output does not necessarily depend on the identifying restriction. It also does not depend on the use of Japan as the regional anchor for EA. Various changes in the specifications of the model produce little difference in the outcome.

The results are surprising given that there is strong evidence that East Asia seems well integrated regionally in both trade and finance. The sizes of intra-regional trade and direct investment are high. Financial markets seem fairly well integrated with those of the U.S. and Japan. Nonetheless, our results indicate that each country in the region seems sufficiently unique, perhaps due to different resource dependencies, growth experiences and/or economic policies. The apparent trade integration thus far has not produced as homogenous a group within the region as has occurred in Western Europe. Although there is some indication that regional shocks became more important in the recent period than before, disturbances are still dominated by country-specific shocks. 
An implication of this study is that a common currency peg (in tight form or with a narrow band) would be more costly in East Asia than in the EMU countries. Uncorrelated country-specific shocks require changes in relative prices among countries. Sluggish price adjustment in the absence of nominal exchange rate adjustment may mean slow recovery from such shocks. Given the overall reluctance to float their currencies and heightened interest in regional financial security after the crisis of 1997, an optimal exchange rate regime in East Asia is not likely to be a full-fledged float and the search for a joint exchange rate arrangement is expected to continue. If this study were of any guide to the search, allowing sufficient flexibility among participants would be necessary in an interim arrangement.

Some caveats remain. First, the exclusion of key countries such as China and Thailand due to insufficient data is a main drawback as it would be difficult to imagine a common currency peg in the region without including them, especially China. Second, assessing OCA criteria using past data might be misleading as income correlation depends on trade integration which in turn is likely to be furthered by a joint exchange rate arrangement. (Frankel and Rose, 1998) The problem would probably be more serious in East Asia where rapid growth and remarkable transformation of the economy is more or less commonplace. More research is warranted, preferably using high quality data for a more recent period. 


\section{References}

Aggarwal, R. and M. Mougoue. "Cointegration among Southeast Asian and Japanese Currencies." Economics Letters 41 (January 1993): 161-166.

Bayoumi, Tamim, and Barry Eichengreen. “One Money or Many? Analyzing the Prospects for Monetary Unification in Various Parts of the World.” Princeton Studies in International Finance no. 76 (1994), Princeton University.

. "Ever Closer to Heaven? An Optimum-Currency-Area Index for European Countries.” European Economic Review 41 (April 1997): 761-770.

. "Shocking Aspects of European Monetary Integration." in Francisco Torres and Francesco

Giavazzi (eds.), Adjustment and Growth in the European Monetary Union, 193-229. Cambridge:

Cambridge University Press, 1993.

Benassy-Quere, Agnes. "Exchange Rate Regimes and Policies: an Empirical Analysis.” in Stefan

Collignon, Jean Pisani-Ferry and Yung Chul Park (eds), Exchange Rate Policies in Emerging Asian

Countries, 40-64. London: Routledge, 1999.

Blanchard, Olivier J., and Quah, Danny. “The Dynamic Effects of Aggregate Demand and Supply

Disturbances." American Economic Review 79 (September 1989): 655-673.

Chinn, Menzie, and Jeffrey A. Frankel. "Who Drives Real Interest Rates around the Pacific Rim: the USA or Japan?” Journal of International Money and Finance 14 (December 1995): 801-821.

De Grauwe, Paul. The Economics of Monetary Integration, $3^{\text {rd }}$ ed. Oxford: Oxford University Press, 1997.

Dornbusch and Park. "Flexibility or Nominal Anchor?" in Stefan Collignon, Jean Pisani-Ferry and Yung Chul Park (eds), Exchange Rate Policies in Emerging Asian Countries, 3-34. London: Routledge, 1999. 
Eichengreen, Barry, and Tamim Bayoumi. "Is Asia an Optimum Currency Area? Can It Become One?" in Stefan Collignon, Jean Pisani-Ferry and Yung Chul Park (eds), Exchange Rate Policies in Emerging Asian Countries, 347-366. London: Routledge, 1999.

Faust, Jon, and Eric M. Leeper. "When do long-run restrictions give reliable results?” Journal of Business and Economic Statistics 15 (July 1997): 345-353.

Frankel, Jeffrey A. "Is Japan Creating a Yen Bloc in East Asia and the Pacific?” in Jeffrey Frankel and Miles Kahler (eds.), Regionalism and Rivalry: Japan and the U.S. in Pacific Asia. Chicago:

University of Chicago Press, 1993. and Andrew Rose. "The Endogeneity of the Optimum Currency Area Criterion.” Economic Journal 108 (July 1998): 1009-1025.

Frankel, Jeffrey A., and Shang-Jin Wei. "Yen Bloc or Dollar Bloc? Exchange Rate Policies of the East Asian Economies." in Takatoshi Ito and Anne O. Krueger (eds.), Macroeconomic Linkages: Savings, Exchange Rates and Capital Flows, 295-334. Chicago: University of Chicago Press, 1994.

Fukuda, S. "The Determinants of Invoice Currencies in Japan: Foreign Trade with East Asian Countries." in T. Ito and A. Krueger (eds.) Macroeconomic Linkage: Savings, Exchange Rates, and Capital Flows, University of Chicago Press, 1996.

Goto, Junichi, and Koichi Hamada. “Economic Preconditions for Asian Regional Integration,” in Takatoshi Ito and Anne O. Krueger (eds.), Macroeconomic Linkages: Savings, Exchange Rates and Capital Flows, 359-385. Chicago: University of Chicago Press, 1994.

Kenen, Peter. "The Theory of Optimum Currency Area: An Eclectic View," in R. Mundell and A. Swoboda (eds.), Monetary Problems in the International Economy. Chicago: University of Chicago Press, 1969.

King, Robert G., Plosser, Charles I., Stock, James H., and Watson, Mark. "Stochastic Trends and Economic Fluctuations.” American Economic Review 81 (September 1991): 819-840. 
Kohsaka, Akira. "Interdependence through Capital Flows in Pacific Asia and the Role of Japan." in Takatoshi Ito and Anne O. Krueger (eds.), Financial Deregulation and Integration in East Asia, 107146. Chicago: University of Chicago Press, 1996.

Kwan, C. H. Economic Interdependence in the Asia-Pacific Region. London: Routledge, 1994.

Kwiatkowski, D., P. Phillips, P. Schmidt, and Y. Shen. "Testing the Null Hypothesis of Stationarity Against the Alternative of a Unit Root.” Journal of Econometrics 54 (October 1992): 159-178.

McKinnon, Ronald I. “Optimum Currency Areas.” American Economic Review 53 (September 1963): $717-724$.

. "After the Crisis, the East Asian Dollar Standard Resurrected: An Interpretation of HighFrequency Exchange Rate Pegging.” Department of Economics, Stanford University, (2000).

Mundell, Robert. “A Theory of Optimum Currency Areas.” American Economic Review 51 (September 1961): 657-665.

Obstfeld, Maurice. "EMU: Ready or Not?” Essays in International Finance, No. 209 (1998), Princeton University.

Phylaktis, Kate. "Capital Market Integration in the Pacific Basin Region: An Impulse Response Analysis.” Journal of International Money and Finance 18 (February 1999): 267-287.

Rogers, John H. "Monetary Shocks and Real Exchange Rates.” Board of Governors of the Federal Reserve System, International Finance Discussion Paper No.612 (1998).

Stockman, Alan. "Sectoral and National Aggregate Disturbances to Industrial Output in Seven Industrial Countries.” Journal of Monetary Economics 21 (March/May 1988): 387-410.

Tse, Y. K. and L. K. Ng. "The Cointegration of Asian Currencies Revisited.” Japan and the World Economy 9 (March 1997): 109-114.

Williamson, John. “The Case for a Common Basket Peg for East Asian Currencies?” in Stefan Collignon, Jean Pisani-Ferry and Yung Chul Park (eds), Exchange Rate Policies in Emerging Asian Countries, 327-343. London: Routledge, 1999. 
$\underline{\text { Table 1. Variance Decompositions }}$

$\underline{\text { A. Europe }}$

\begin{tabular}{lrrrr}
\hline \hline & & \multicolumn{3}{c}{ Y-D } \\
\cline { 3 - 5 } & Qtrs & U-G & U-R & U-D \\
\hline \multirow{2}{*}{ Group I } & & & & \\
Austria & 4 & 1.6 & 52.7 & 45.7 \\
& 20 & 3.1 & 75.6 & 21.3 \\
Belgium & 4 & 5.0 & 45.0 & 50.0 \\
& 20 & 10.3 & 54.2 & 35.5 \\
Denmark & 4 & 10.3 & 33.2 & 56.6 \\
& 20 & 15.3 & 39.7 & 45.0 \\
France & 4 & 2.9 & 36.4 & 60.7 \\
& 20 & 5.6 & 57.3 & 37.0 \\
Ireland & 4 & 18.4 & 7.7 & 73.8 \\
& 20 & 30.7 & 5.8 & 63.5 \\
Italy & 4 & 14.7 & 13.1 & 72.2 \\
& 20 & 31.7 & 16.1 & 52.1 \\
Netherlands & 4 & 3.0 & 42.2 & 54.7 \\
& 20 & 5.8 & 50.5 & 43.7
\end{tabular}

Group II

\begin{tabular}{lrrrr} 
Finland & 4 & 4.1 & 10.4 & 85.5 \\
& 20 & 18.6 & 6.1 & 75.2 \\
Greece & 4 & 25.0 & 23.7 & 51.3 \\
& 20 & 25.8 & 35.0 & 39.2 \\
Norway & 4 & 1.3 & 8.5 & 90.2 \\
& 20 & 3.1 & 5.5 & 91.4 \\
Portugal & 4 & 19.4 & 13.8 & 66.8 \\
& 20 & 26.2 & 33.7 & 40.1 \\
Spain & 4 & 14.7 & 22.6 & 62.7 \\
& 20 & 31.8 & 25.4 & 42.8 \\
Sweden & 4 & 1.8 & 15.1 & 83.1 \\
& 20 & 16.1 & 6.2 & 77.8 \\
Switzerland & 4 & 1.5 & 24.3 & 74.2 \\
& 20 & 9.1 & 49.8 & 41.1 \\
U.K. & 4 & 9.6 & 30.1 & 60.3 \\
& 20 & 36.0 & 11.2 & 52.8 \\
\hline \hline
\end{tabular}

$\underline{\text { B. East Asia }}$

\begin{tabular}{lrrrr}
\hline \hline & & \multicolumn{3}{c}{ Y-D } \\
\cline { 3 - 5 } & Qtrs & U-G & U-R & U-D \\
\hline \multirow{2}{*}{ Hong Kong } & 4 & 16.7 & 6.1 & 77.2 \\
& 20 & 15.3 & 7.4 & 77.4 \\
Indonesia & 4 & 10.1 & 15.0 & 74.9 \\
& 20 & 6.1 & 10.6 & 83.3 \\
Korea & 4 & 33.9 & 2.0 & 64.2 \\
& 20 & 18.5 & 1.8 & 79.6 \\
Malaysia & 4 & 11.2 & 1.2 & 87.6 \\
& 20 & 35.9 & 1.4 & 62.8 \\
Philippines & 4 & 5.7 & 17.6 & 76.7 \\
& 20 & 15.2 & 13.3 & 71.5 \\
Singapore & 4 & 9.2 & 12.3 & 78.5 \\
& 20 & 13.3 & 3.7 & 83.0 \\
Taiwan & 4 & 26.3 & 27.3 & 46.4 \\
& 20 & 28.1 & 10.1 & 61.7 \\
\hline \hline
\end{tabular}

Note: Reported are the variance decompositions of forecast errors for domestic output for Europe and East Asia at the 4- and 20-quarter forecast horizons. "U-G," "U-R" and "U-D" denote global, regional, and local shocks, respectively. 
$\underline{\text { Table 2. Variance Decompositions of Domestic Output in Sub-Periods }}$

\begin{tabular}{|c|c|c|c|c|c|c|c|c|c|}
\hline & \multicolumn{3}{|c|}{ U-G } & \multicolumn{3}{|c|}{ U-R } & \multicolumn{3}{|c|}{ U-D } \\
\hline & WP & Per I & Per II & WP & Per I & Per II & WP & Per I & Per II \\
\hline \multicolumn{10}{|l|}{ Europe } \\
\hline Core & 6.2 & 8.1 & 8.7 & 59.4 & 59.9 & 58.4 & 34.4 & 32.0 & 32.9 \\
\hline Non-Core & 22.2 & 22.9 & 21.0 & 21.3 & 34.1 & 28.9 & 56.5 & 42.9 & 52.8 \\
\hline EMU & 18.2 & 20.5 & 17.6 & 36.1 & 41.9 & 45.5 & 45.7 & 37.6 & 36.9 \\
\hline Non-EMU & 17.6 & 16.7 & 17.9 & 24.6 & 39.7 & 23.7 & 57.9 & 43.6 & 63.5 \\
\hline \multicolumn{10}{|l|}{$\underline{\text { East Asia }}$} \\
\hline Hong Kong & -- & -- & 15.3 & -- & -- & 7.3 & -- & -- & 77.4 \\
\hline Indonesia & -- & -- & 6.1 & -- & -- & 10.6 & -- & -- & 83.3 \\
\hline Korea & 18.5 & 29.7 & 0.9 & 1.8 & 20.1 & 29.8 & 79.6 & 50.2 & 69.3 \\
\hline Malaysia & 35.9 & 53.7 & 0.4 & 1.4 & 3.9 & 9.9 & 62.8 & 42.4 & 89.7 \\
\hline Philippines & -- & -- & 15.2 & -- & -- & 13.3 & -- & -- & 71.5 \\
\hline Singapore & 13.3 & 36.7 & 0.8 & 3.7 & 7.2 & 24.8 & 83.0 & 56.1 & 74.3 \\
\hline Taiwan & 28.1 & 68.1 & 3.2 & 10.1 & 6.0 & 2.6 & 61.7 & 25.9 & 94.2 \\
\hline
\end{tabular}

Note: (a) WP, Per I and Per II represent whole, first and second periods respectively. For Europe, the respective time spans are 1965:1 to 1997:1, 1965:1 to 1979:1 and 1979:2 to 1997:1. The corresponding sample periods for East Asia are 1971:1 to 1997:1, 1971:1 to 1984:1 and 1984:2 to 1997:1. (b) Variance decompositions are for 20-quarter horizon. (c) Results for the first sub-period are not reported for various East Asian countries due to insufficient data. 
Table 3. Correlations of Aggregate Supply and Aggregate Demand Shocks

A. Europe

\begin{tabular}{lcc}
\hline \hline & AS Shocks & AD Shocks \\
\hline Group I & & \\
Austria & .239 & .307 \\
Belgium & .370 & .332 \\
Denmark & .259 & .269 \\
France & .230 & .249 \\
Ireland & .217 & .132 \\
Italy & .201 & .101 \\
Netherlands & .093 & .242 \\
(Average) & $(.230)$ & $. .233)$ \\
Group II & & \\
Finland & .204 & .069 \\
Greece & .049 & .004 \\
Norway & .091 & -.066 \\
Portugal & .054 & .167 \\
Spain & .192 & .317 \\
Sweden & .109 & .184 \\
Switzerland & .372 & .209 \\
U.K. & .308 & .189 \\
\hline \hline
\end{tabular}

B. East Asia

\begin{tabular}{lccccccc}
\hline \hline & \multicolumn{3}{c}{ AS Shocks } & & \multicolumn{3}{c}{ AD Shocks } \\
\cline { 2 - 3 } \cline { 6 - 8 } & Japan & US & G3 & & Japan & US & G3 \\
\hline Hong Kong & -.156 & -.217 & -.069 & & -.368 & .196 & -.057 \\
Indonesia & -.121 & -.086 & .008 & & .148 & .128 & .137 \\
Korea & .039 & .114 & .119 & & .151 & -.115 & .128 \\
Malaysia & .054 & -.060 & .105 & & .258 & .045 & .196 \\
Philippines & -103 & -.010 & .038 & & .134 & -.052 & .139 \\
Singapore & .141 & .051 & .250 & & .260 & -.015 & .146 \\
Taiwan & .437 & .236 & .235 & & .306 & -.030 & .249 \\
\hline \hline
\end{tabular}


Table 4: Variance Decompositions in Alternative Models: East Asia

\begin{tabular}{|c|c|c|c|c|c|c|c|c|}
\hline & & $\mathrm{BM}$ & M1 & M2 & M3 & M4 & M5 & M6 \\
\hline \multirow{3}{*}{ Hong Kong } & U-G & 15.3 & 1.1 & 2.0 & -- & 8.1 & -- & -- \\
\hline & U-R & 7.4 & 0.2 & 1.1 & -- & 8.2 & 6.0 & 16.9 \\
\hline & U-D & 77.4 & 98.7 & 96.9 & -- & 83.8 & 94.0 & 83.1 \\
\hline \multirow[t]{3}{*}{ Indonesia } & U-G & 6.1 & 1.4 & 1.4 & 58.6 & 9.1 & -- & -- \\
\hline & U-R & 10.6 & 2.5 & 2.6 & 23.8 & 9.7 & 10.1 & 10.8 \\
\hline & U-D & 83.3 & 96.1 & 96.0 & $16.4 / 1.2$ & 81.2 & 89.9 & 89.2 \\
\hline \multirow[t]{3}{*}{ Korea } & U-G & 18.5 & 0.8 & 1.2 & 2.4 & 10.5 & -- & -- \\
\hline & U-R & 1.8 & 5.0 & 4.0 & 3.2 & 2.0 & 11.0 & 25.4 \\
\hline & U-D & 79.6 & 94.2 & 94.8 & $94.2 / 0.3$ & 87.5 & 89.0 & 74.6 \\
\hline \multirow[t]{3}{*}{ Malaysia } & U-G & 35.9 & 47.9 & 46.9 & 32.2 & 39.4 & -- & -- \\
\hline & U-R & 1.4 & 3.9 & 3.1 & 1.2 & 2.5 & 39.6 & 41.4 \\
\hline & U-D & 62.8 & 48.2 & 50.1 & $62.1 / 4.4$ & 58.0 & 60.4 & 58.6 \\
\hline \multirow[t]{3}{*}{ Philippines } & U-G & 15.2 & 4.9 & 11.7 & 5.8 & 33.9 & -- & -- \\
\hline & U-R & 13.3 & 8.5 & 15.2 & 9.3 & 2.4 & 37.3 & 23.5 \\
\hline & U-D & 71.5 & 86.5 & 73.1 & $77.4 / 7.6$ & 63.7 & 62.7 & 76.5 \\
\hline \multirow[t]{3}{*}{ Singapore } & U-G & 13.3 & 15.2 & 14.7 & 2.0 & 14.8 & -- & -- \\
\hline & U-R & 3.7 & 1.9 & 1.9 & 0.7 & 1.2 & 29.7 & 21.6 \\
\hline & U-D & 82.0 & 82.9 & 83.4 & $94.9 / 2.4$ & 84.0 & 70.3 & 78.4 \\
\hline \multirow[t]{3}{*}{ Taiwan } & U-G & 28.1 & 0.8 & 1.3 & 14.6 & 27.4 & -- & -- \\
\hline & U-R & 10.1 & 4.2 & 3.0 & 4.3 & 8.2 & 35.6 & 46.0 \\
\hline & U-D & 61.7 & 95.0 & 95.7 & $78.8 / 2.3$ & 64.5 & 64.4 & 54.0 \\
\hline
\end{tabular}

Note: (a) BM is the benchmark model; M1 uses the Choleski decomposition; M2 incorporates the exogeneity restrictions; M3 is a 4-variable model including the price level; M4 uses a weighted average of U.S. and German outputs for global output and a weighted average of outputs of Japan, Korea, Taiwan, Malaysia, and Singapore for regional output; M5 is a two-variable model with a weighted average of U.S., Japanese and German outputs as regional output (and no global output); M6 uses U.S. output as regional output. (b) M3 is not estimated for Hong Kong due to insufficient price data. 


\section{Footnotes}

${ }^{1}$ A common currency peg may mean many different arrangements. In this paper, the term is used as an area in which member countries tie with a narrow band (e.g., 5-10 percent) their currencies to a chosen currency (yen, dollar, or a composite currency). This may include more radical options such as a currency board or a currency union but we focus on "joint" and "pegging” aspects of the arrangement.

${ }^{2}$ For the ease of exposition, we omit log-difference in our description of variables. For instance, domestic output means log-difference of domestic output. The same applies to the price level below.

${ }^{3}$ Data for Hong Kong, Indonesia and Taiwan are obtained from Hong Kong Monthly Digest of Statistics, Economic Indicators, Monthly Statistical Bulletin, Indonesia, and Directorate -General of Budget, Accounting and Statistics, Executive Yuan (at the website http://www.dgbasey.gov.tw/dgbas03/bs8/dbase/data.htm) respectively.

${ }^{4}$ Supporting evidence is summarized in an appendix to the paper and available upon request from the authors. The appendix includes the results of unit-root and cointegration tests, variance decompositions of global and regional outputs as well as domestic output, and, for a selected group of countries, impulse response functions. In empirical analysis, we take into consideration the uncertainty about the nonstationarity of output series. When applicable, we consider two different methods of detrending: first differencing and the Hodrick-Prescott filter. The qualitative results do not depend on the detrending method.

${ }^{5}$ We choose 20-quarter decomposition as it roughly corresponds to business cycle frequency. Choosing different forecast horizons makes little change in the results as variance decompositions stabilize quickly in 8 to 10 quarters.

${ }^{6}$ BE1 indices in descending order are as follows: Netherlands (0.003), Belgium (0.003), Austria (0.008), Switzerland (0.038), Ireland (0.043), Greece (0.053), Denmark (0.063), Sweden (0.068), Portugal (0.068), France (0.068), Italy (0.070), Norway (0.078), Spain (0.088), Finland (0.098), and the U.K. (0.099)

${ }^{7}$ The corresponding indices (versus Japan) for East Asia are as follows: Singapore (0.063) Hong Kong (0.068), Taiwan (0.087), South Korea (0.090), Thailand (0.090), Malaysia (0.093), Philippines (0.094), and Indonesia (0.106).

${ }^{8}$ This does not mean that EB (1999) would recommend a common currency peg for EA. Instead, they point out that weak financial systems, loose political networks and the lack of long integrationist tradition would make a common currency peg a very unstable and unsatisfactory arrangement. 


\footnotetext{
${ }^{9}$ While their study introduces other measures - such as factor mobility, the speed of adjustment, and the relative size of structural shocks - to examine OCA criteria, the coefficient of correlation of supply shocks appear to be the most representative statistic of all and other relevant measures seem to be highly correlated with it.

${ }^{10}$ We can offer some arguments in defense of the benchmark model. First, the exogeneity restrictions appear too severe. That Japan or EA region is too small to affect the global economy in all horizons seems unwarrantedly strong. Secondly, the contemporaneous restrictions used in the conventional decomposition give too much emphasis on timing of initial shocks regardless of their dynamic impacts. For instance, correlated shocks across the region may be classified as local if other countries in the region experience the same shock with a lag. Also, as financial shocks are expected to transmit more quickly than real shocks, they are likely to be captured as regional or global shocks under the scheme while real shocks are more easily classified as local.
} 